\title{
Molecular changes in articular cartilage and subchondral bone in the rat anterior cruciate ligament transection and meniscectomized models of osteoarthritis
}

\author{
Maureen Pickarski ${ }^{\dagger}$, Tadashi Hayami ${ }^{\dagger}$, Ya Zhuo and Le T Duong ${ }^{*}$
}

\begin{abstract}
Background: Osteoarthritis $(\mathrm{OA})$ is a debilitating, progressive joint disease.

Methods: Similar to the disease progression in humans, sequential events of early cartilage degradation, subchondral osteopenia followed by sclerosis, and late osteophyte formation were demonstrated in the anterior cruciate ligament transection (ACLT) or ACLT with partial medial meniscectomy (ACLT + MMx) rat OA models. We describe a reliable and consistent method to examine the time dependent changes in the gene expression profiles in articular cartilage and subchondral bone.

Results: Local regulation of matrix degradation markers was demonstrated by a significant increase in mRNA levels of aggrecanase-1 and MMP-13 as early as the first week post-surgery, and expression remained elevated throughout the 10 week study. Immunohistochemistry confirmed MMP-13 expression in differentiated chondrocytes and synovial fibroblasts at week-2 and cells within osteophytes at week-10 in the surgically-modifiedjoints. Concomitant increases in chondrocyte differentiation markers, Col IIA and Sox 9, and vascular invasion markers, VEGF and CD31, peaked around week-2 to -4 , and returned to Sham levels at later time points in both models. Indeed, VEGF-positive cells were found in the deep articular chondrocytes adjacent to subchondral bone. Osteoclastic bone resorption markers, cathepsin K and TRAP, were also elevated at week-2. Confirming bone resorption is an early local event in OA progression, cathepsin $\mathrm{K}$ positive osteoclasts were found invading the articular cartilage from the subchondral region at week 2 . This was followed by late disease events, including subchondral sclerosis and osteophyte formation, as demonstrated by the upregulation of the osteoanabolic markers runx 2 and osterix, toward week-4 to 6 post-surgery.
\end{abstract}

Conclusions: In summary, this study demonstrated the temporal and cohesive gene expression changes in articular cartilage and subchondral bone using known markers of OA progression. The findings here support genome-wide profiling efforts to elucidate the sequential and complex regulation of the disease.

Keywords: osteoarthritis, subchondral bone, cartilage degeneration, bone remodeling

\section{Background}

Osteoarthritis (OA) is a joint disease that involves degeneration of cartilage, limited synovitis, subchondral bone changes, and osteophyte formation [1]. Mechanical stress associated with joint instability is thought to

\footnotetext{
* Correspondence: le.duong@merck.com

+ Contributed equally

Merck Sharpe \& Dohme Corp., Bone Biology Group, West Point, PA 19486, USA
}

(C) 2011 Pickarski et al; licensee BioMed Central Ltd. This is an Open Access article distributed under the terms of the Creative Commons Attribution License (http://creativecommons.org/licenses/by/2.0), which permits unrestricted use, distribution, and reproduction in any medium, provided the original work is properly cited. induce changes in biochemical factors within affected joints leading to focal articular cartilage degradation [2]. However, recent evidence indicates that it is also necessary to consider the contributions of synovial inflammation and subchondral bone changes [3]. The integrity of the articular cartilage has been proposed to depend on the biomechanical properties of the underlying bone [4]. Subchondral bone changes detected by $99 \mathrm{mTc}$ scintigraphy appeared to precede radiographic signs of structural 
damage in nodal OA joints [5]. More recent studies have documented acceleration of subchondral bone turnover accompanied by specific architectural changes in the subchondral trabecular bone of the OA joints [6-9]. Furthermore, epidemiologic studies have correlated both the increases in bone mineral density and in the rate of bone turnover, as determined by biochemical markers, with increases in the incidence and severity of osteoarthritis [10-12]. Because the subchondral bone is critically important in containing the mechanical abnormalities that damage the cartilage, emphasis on a panel of biomarkers of bone remodeling resulting from the abnormal stresses on the joint has been proposed as diagnostic tools used to monitor treatment responses to potential structure-modifying drugs [13,14]. The mechanical and biochemical properties of the subchondral bone are therefore of particular interest in any attempt to determine the molecular mechanisms responsible for initiating osteoarthritis.

Currently, no OA animal models fully mimic the pathogenesis of the human disease and the surgical models of mechanical instability appear to represent chronic, traumatic OA. Among these models, the anterior cruciate ligament transection model in dogs and the partial menisci resection model in rabbits have been widely used to study the histological and biochemical changes occurring during OA progression [15]. As the metabolism of articular cartilage and particularly of the subchondral bone in these species is not completely understood, further analysis of molecular changes in the joints of these species during disease progression is warranted. We have previously reported the characterization of the morphological and histological changes in cartilage and subchondral bone in two different models of surgicallyinduced $\mathrm{OA}$ in the rat, the anterior cruciate ligament transection (ACLT) model or the ACLT in combination with partial medial meniscectomy (ACLT+MMx) [16]. In both models, OA-related pathogenic changes occurred in a time dependent manner with milder and slower disease progression in ACLT, as compared with ACLT+MMx. Surface cartilage damage and accelerated subchondral bone resorption were observed within 2-weeks post-surgery. Significant cartilage thinning, subchondral sclerosis and osteophyte formation were demonstrated as late stage disease events. Here, we focus on evaluating molecular changes of OA progression in these two surgicallyinduced models of joint instability in rats in order to further our understanding of the relationship between subchondral bone changes and cartilage degradation.

\section{Methods}

\section{Osteoarthritis model and treatment}

All procedures were carried out in accordance with the Institutional Animal Care and Use Committee in Merck
Research Labs. A total of 144 intact male Sprague-Dawley rats (Taconic, NY) were used in three time course studies.

Detailed development and characterization of the osteoarthritis (OA) models were previously reported [16]. In brief, the two OA models were surgically induced in 10 week-old male rat right knee joints with some modifications. Rats were anesthetized with isoflurane. After shaving the right knee joint, the skin was disinfected with iodine. The knee joint was exposed though the medial parapatellar approach. The patella was dislocated laterally and the knee placed in full flexion. The anterior cruciate ligament (ACL) was then transected with micro-scissors; complete transection was confirmed with the anterior drawer test. In the more severe model of OA, anterior cruciate ligament transection (ACLT) with partial medial meniscectomy $(\mathrm{ACLT}+\mathrm{MMx})$, the medial collateral ligament was additionally transected with resection of medial meniscus. Following surgery, the joint surface was washed with sterile saline solution, and both capsule and skin were sutured using Vicryl 4-0 (Ethicon, Edinburgh, UK), absorbable suture and monofilament 4-0 Nylon threads (Ethicon, Edinburgh, UK).

In the sham operation, after subluxation of patella with the same procedure as OA model, the wound was closed by layers. All operation procedures were performed using a surgical loupe. Buprenorphine hydrochloride $(0.1 \mathrm{mg} / \mathrm{kg})$ (Reckitt \& Colman Products Ltd., Hull, England) was given as a post-operative analgesic. Rats were allowed to move freely in the soft bedding in plastic cages.

The initial time-course study followed the animals for 1-, 2-, 4-, 6-, and 10-wk post-surgery. Two repeat timecourse studies were performed for 2-, 4-, and 10-wk and 1-, 2-, and 10-wk post-surgery, respectively. Each of the study groups had six animals for each time point.

\section{RNA collection}

The surgical (right) and contra-lateral (left) tibiae from each group (Sham, ACLT, ACLT+MMx) were rapidly dissected from animals at 1, 2, 4, 6, and 10-wk post-surgery. Tibiae were thoroughly cleaned to remove muscle and ligament as well as joint capsule, without causing undue damage to the tibia plateau. Each tibia was then mounted in a precision bone saw such that the medial side of the bone was oriented parallel to the holding clamp, while the head of the bone was oriented perpendicular to the clamp. Using an Isomet low speed bone saw (Beuhler, Lake Bluff, IL) three cuts were made from the end of each tibia. Slice \#1: was approximately 960 $\mu \mathrm{m}$ from the tibial plateau and contained articular cartilage $(\sim 200 \mu \mathrm{m})$ and subchondral bone $(\sim 760 \mu \mathrm{m})$. Slice \#2: was approximately $1440 \mu \mathrm{m}$ and contained epiphyseal bone $(\sim 1060 \mu \mathrm{m})$ and growth plate $(\sim 280 \mu \mathrm{m})$. 
Slice \#3: was also approximately $1440 \mu \mathrm{m}$ and contained metaphyseal bone. Each bone slice was placed in saline and flushed with a 23 gauge needle to remove bone marrow. They were quickly frozen in liquid nitrogen and stored at $-135^{\circ} \mathrm{C}$ until processing. The whole process of tissue collection normally took less than 10 minutes from necropsy to freezing of the cartilage and bone slices. Bone slices were pooled for each cut within a group.

\section{RNA isolation from Bone and Cartilage}

Frozen bone slices were immersed in liquid nitrogen and then crushed prior to addition to Trizol reagent (Invitrogen, CA). Samples were homogenized using a Polytron (Brinkman Instruments). Total RNA was isolated according to manufacturer's directions with minor modifications. Following the chloroform extraction step, RNA was re-extracted with acidic phenol:chloroform to remove proteoglycans. RNA was precipitated with isopropanol and washed with $75 \%$ ethanol. After pellet was air-dried, RNA was resuspended in molecular biology grade water and concentration of each sample was determined by measuring the absorbance at $260 \mathrm{~nm}$. Agarose gel electrophoresis was used to confirm RNA integrity.

\section{TaqMan probes and primers}

Primers and fluorogenic probes were designed using Primer Express v. 1.0 (Applied Biosystems, CA) and are listed in Table 1. All probes were synthesized by Applied Biosystems with the fluorescent reporter dye FAM (6-carboxy-fluorescein) attached to the 5'-end and the quencher dye TAMRA (6-carboxy-tetramethyl-rhodamine) attached to the 3'-end. When genomic sequence was available, primers and probes were designed to span intron-exon boundaries. Amplified products were designed to be between 70-110 bp.

All primer/probe pairs were checked for efficiency of amplification using reverse transcribed rat bone total RNA. Standard curves were generated using serial dilutions of known quantities of total RNA in duplicate.

\section{Reverse transcription and TaqMan real-time quantitative PCR}

Reverse transcription (RT) reactions were carried out for each RNA sample in MicroAmp reaction tubes using TaqMan reverse transcription reagents. Each reaction tube contained $250 \mathrm{ng}$ of total RNA in a volume of 50 $\mu \mathrm{L}$ containing $1 \times$ TaqMan $\mathrm{RT}$ buffer, $5.5 \mathrm{mM} \mathrm{MgCl}_{2}$, $500 \mu \mathrm{M}$ of each dNTP, $2.5 \mu \mathrm{M}$ of oligo-d(T)16 primers, $2.5 \mu \mathrm{M}$ of random hexamers, $0.4 \mathrm{U} / \mu \mathrm{L}$ RNase inhibitor and $1.25 \mathrm{U} / \mu \mathrm{L}$ MultiScribe Reverse Transcriptase. RT reaction was carried out at $25^{\circ} \mathrm{C}$ for $10 \mathrm{~min}, 48^{\circ} \mathrm{C}$ for 30 min and $95^{\circ} \mathrm{C}$ for $5 \mathrm{~min}$. The $\mathrm{RT}$ reaction mixture was then placed at $4^{\circ} \mathrm{C}$ for immediate use in PCR amplification or stored at $-20^{\circ} \mathrm{C}$.

Real-time PCR was performed in a MicroAmp Optical 96-well reaction plate. For each $50 \mu \mathrm{L}$ reaction, $10 \mu \mathrm{L}$ of RT product (50 ng total RNA), $100 \mathrm{nM}$ forward primer, $100 \mathrm{nM}$ reverse primer, $200 \mathrm{nM}$ probe and $1 \times$ Universal Master Mix (Applied Biosystems) were combined. Amplification conditions were $2 \mathrm{~min}$ at $50^{\circ} \mathrm{C}, 10 \mathrm{~min}$ at $95^{\circ} \mathrm{C}$ followed by 40 cycles at $95^{\circ} \mathrm{C}$ for $15 \mathrm{sec}, 60^{\circ} \mathrm{C}$ for 1 min. All reactions were performed in ABI Prism 7700 Sequence Detection System in duplicate. Data collected represents an average from replicate studies for week 1, 2, 4, and 10 and one study for week 6. Expression levels of mRNA were corrected for expression relative to the housekeeping gene, Cyclophilin A, and were expressed as fold change relative to sham levels.

\section{Immunohistochemistry}

Resected knee joints were fixed with $4 \%$ paraformaldehyde (Merck, Darmstadt, Germany) in $0.1 \mathrm{M}$ phosphate buffer solution $\left(\mathrm{pH} \mathrm{7.5)}\right.$ for 24 hours at $4^{\circ} \mathrm{C}$. After the fixation, the tissues were rinsed with PBS. Tissues were decalcified in $0.5 \mathrm{M}$ ethylene diamine tetra acetate (EDTA) solution ( $\mathrm{pH} 7.6)$ with stirring in $4^{\circ} \mathrm{C}$, then dehydrated in a graded ethanol series and defatted in chloroform to embed into the paraffin wax (Fisher Scientific, NJ, USA). Normal and OA cartilage specimens were examined by histological analysis and immunohistochemistry.

All tissues from the first time course study were processed for tissue sections and randomly selected from each group $(\mathrm{N}=6)$ for immunohistochemical evaluations. Tissue sections were deparaffinized in xylene, hydrated in graded ethanol, then treated with $500 \mathrm{U} / \mathrm{ml}$ testicular hyaluronidase (Sigma, MO) at $37^{\circ} \mathrm{C}$ for 20 min. Tissue sections were incubated with anti-MMP-13 Ab, a cocktail of anti-MMP-9 polyclonal (Cell Sciences, $\mathrm{MA}$ ) and anti-cathepsin $\mathrm{K}$ (CatK) mAb (Oncogene, CA) or a cocktail of anti-VEGF polyclonal (Neomarkers, CA) and anti-KDR mAb (Accurate chemical \& scientific Co., $\mathrm{NY}$ ). All were incubated overnight at $4^{\circ} \mathrm{C}$, as described previously [17]. For MMP-13 immunostaining, after rinsing in PBS with $0.3 \%$ Tween 20, sections were incubated with biotin-conjugated anti-rabbit Ab (Vector Laboratories, CA) for $30 \mathrm{~min}$, followed by alkaline phosphatase-conjugated streptavidin for $30 \mathrm{~min}$ (Vector Laboratories, CA). These sections were rinsed with PBS, and developed using the fast red substrate system (Dako, CA) for $5 \mathrm{~min}$, counterstained with hematoxylin. Double-labeled immunohistochemical staining for cathepsin K/MMP-9 and VEGF/KDR was performed simultaneously. Briefly, tissue sections were incubated with a cocktail of mouse monoclonal and rabbit polyclonal antibodies, followed by incubation with a cocktail of 
Table 1 Oligonucleotides and TaqMan fluorogenic probes

\begin{tabular}{|c|c|c|c|c|}
\hline Gene & Genebank & Primer & Sequence $5^{\prime}-3^{\prime}$ & Amplicon \\
\hline \multirow[t]{3}{*}{ Aggrecanase-1 } & NM_023959 & Forward & CTGCATCTGCCAGTGACTTITC & 74 \\
\hline & & Reverse & TCAGGACCAAAGGTCAGTTGG & \\
\hline & & Probe & TGGCAAGGACTATGATGCTGACCGC & \\
\hline \multirow[t]{3}{*}{ Bone Sialoprotein } & NM_012587 & Forward & GTTGGAGTTAGCTGCGCTCC & 90 \\
\hline & & Reverse & TCCTCTTCCTCGTCGCTTTCCTTCATT & \\
\hline & & Probe & AAGGCTGGAGATGCAGAGGGCAAGG & \\
\hline \multirow[t]{3}{*}{ Cathepsin K } & NM_031560 & Forward & GCCATGAATCACCTGGGAGA & 76 \\
\hline & & Reverse & GCGAAGGTGGCACTCTGAGT & \\
\hline & & Probe & TGACCAGCGAAGAAGTGGTTCAGAAGATGA & \\
\hline \multirow[t]{3}{*}{ Cbfa-1/Runx2 } & AF325502 & Forward & TGCTTCATTCGCCTCACAA & 71 \\
\hline & & Reverse & CTTGCTGTCCTCCTGGAGAAA & \\
\hline & & Probe & AACCACAGAACCACAAGTGCGGTGC & \\
\hline \multirow[t]{3}{*}{ CD31 } & NM_031591 & Forward & TCAACAGAGCCAGCATTGTGA & 70 \\
\hline & & Reverse & CACGGAGCAAGAAAGACTCTGA & \\
\hline & & Probe & CAGTCTCCGAAGCGGCCCTCTAACA & \\
\hline \multirow[t]{3}{*}{ Collagen Type IIA } & NM_031163 & Forward & TCTGCAGAATGGGCAGAGGTATA & 103 \\
\hline & & Reverse & GATAATGTCATCGCAGAGGACATTC & \\
\hline & & Probe & AAGCCCTCATCTTGCCGCATCTGTG & \\
\hline \multirow[t]{3}{*}{ Cyclophilin A } & NM_017101 & Forward & CAAATGCTGGACCAAACACAA & 70 \\
\hline & & Reverse & GCCATCCAGCCACTCAGTCT & \\
\hline & & Probe & TGGTTCCCAGTIIITATCTGCACTGCC & \\
\hline \multirow[t]{3}{*}{ KDR } & NM_013062 & Forward & ACGTTTGAGAACCTCACGTGG & 84 \\
\hline & & Reverse & CTTGCAAACTGGTGTGAGTGATTC & \\
\hline & & Probe & AGCTTGGCTCACAGGCAACATCGG & \\
\hline \multirow[t]{3}{*}{ MMP-13 } & NM_133530 & Forward & AGTCCTTITGGCCAGAACTTCC & 76 \\
\hline & & Reverse & AAGATGAACATGAGGTCTCGGG & \\
\hline & & Probe & CCATGTGGATGCTGCATACGAGCATC & \\
\hline \multirow[t]{3}{*}{ Osterix } & NM_181374 & Forward & TGACTGCCTGCCTAGTGTCTACA & 94 \\
\hline & & Reverse & ACCTGGTGAGATGCCTGCA & \\
\hline & & Probe & ATGTCCCATCCCTACGGCTCCTGGTA & \\
\hline \multirow[t]{3}{*}{ Osteopontin } & NM_012881 & Forward & TCTGATGAACAGTATCCCGATGC & 84 \\
\hline & & Reverse & GACCTTGATAGCCTCATCGGAC & \\
\hline & & Probe & AGGACCTCACCTCCCGCATGAAGAG & \\
\hline \multirow[t]{3}{*}{ Sox-9 } & AB073720 & Forward & CGCAGGAAGCTGGCAGAC & 76 \\
\hline & & Reverse & GTCTCCAGAGCTTGCCCAGA & \\
\hline & & Probe & CCGCATCTGCACAACGCGGA & \\
\hline \multirow[t]{3}{*}{ TRAP } & NM_019144 & Forward & AATTGCCTACTCCAAGATCTCCAA & 74 \\
\hline & & Reverse & GCGGAACTTTGAAACGCAAA & \\
\hline & & Probe & CGCTGGAACTTCCCCAGCCCTTATTA & \\
\hline \multirow[t]{3}{*}{ VEGF } & NM_031836 & Forward & AGCCCATGAAGTGGTGAAGTTC & 71 \\
\hline & & Reverse & CCACCAGGGTCTCAATTGGA & \\
\hline & & Probe & TGGACGTCTACCAGCGCAGCTATTGC & \\
\hline
\end{tabular}

Exon/intron boundaries are indicated with underlined bases. Exon/intron boundaries for Cathepsin K, TRAP, MMP-9, and VEGF are assumed by comparison to mouse sequence.

biotin-conjugated anti-rabbit $\mathrm{Ab}$ and $\mathrm{HRP}$ conjugated anti mouse antibody (DAKO, CA) for $1 \mathrm{hr}$, and incubated with alkaline phosphatase-conjugated streptavidin for $30 \mathrm{~min}$ (Vector Laboratories, CA). Alkaline phosphatase was colored either blue (VEGF) or red (MMP-9) color with AP blue (Vector Laboratories, CA) or fast red
(DAKO, CA) respectively. They were washed twice with PBS for $1 \mathrm{hr}$, followed by development to brown color

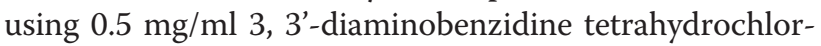
ide. For controls, the same procedures were carried out either without primary Ab or with mouse mAb IgG instead of primary antibody. 


\section{Results}

Collection of articular cartilage and subchondral bone from the surgically induced joint instability models in the rats

In this study, we initially focused on developing a reliable method for serially collecting the articular cartilage and subchondral bone, the epiphyseal and metaphyseal bone slices from the tibeal plateaux of surgically modified (right) and contra-lateral sham-operated (left) joints for RNA processing. A previous study evaluated timedependent macroscopic changes in the surgical joint of both OA models in comparison to Sham; detectable changes in the articular cartilage surface at 6 weeks was noted for both ACLT and ACLT + MMx models [17]. To gauge the depth of discrete tissue layers, toluidine blue sections of tibiae from age-matched animals were examined. The resulting measurements were used to calibrate the precision bone saw used for tissue collection for RNA processing. As shown in Figure 1, slice 1 contains the articular cartilage and the proximal subchondral bone layer, collected from the first $960 \mu \mathrm{m}$ measured from the tibial surface; slice 2 contains mostly the epiphyseal bone and growth plate, spanned the next $1440 \mu \mathrm{m}$; and slice 3 contains the metaphyseal bone, collected from the adjacent $1440 \mu \mathrm{m}$.

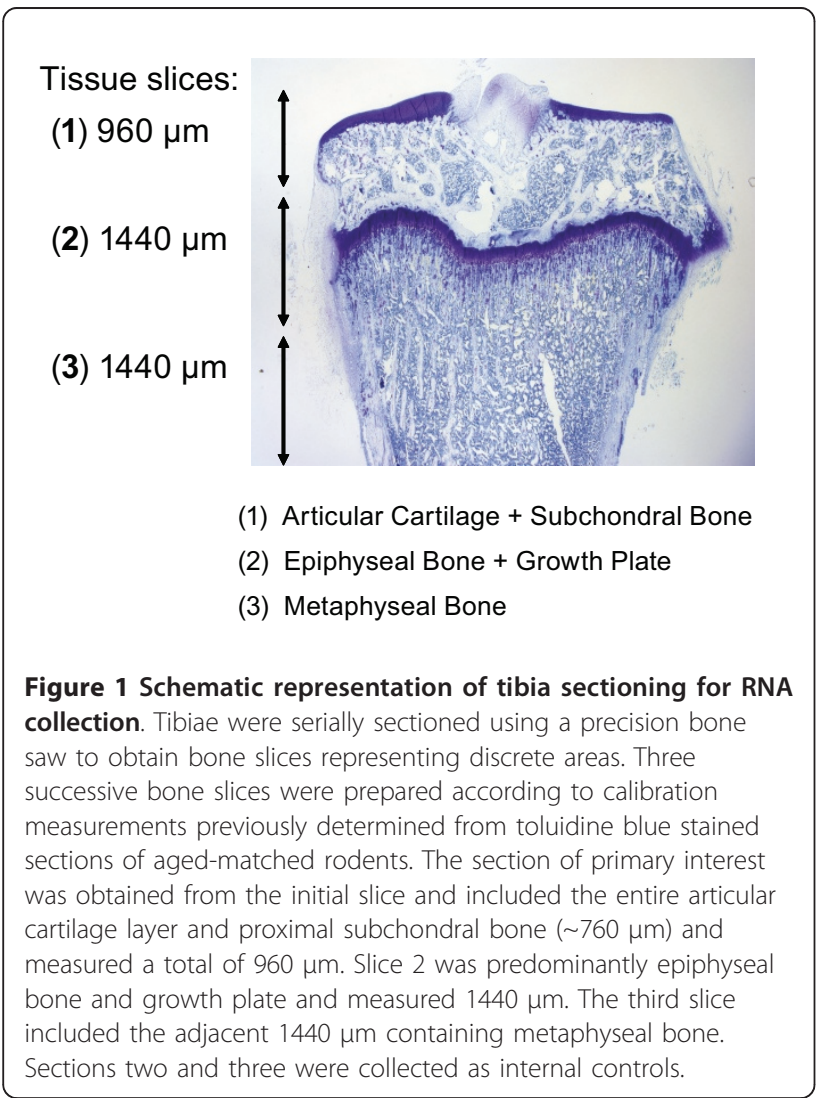

From a study with aged matched rats subjected to either sham-operated, or to anterior cruciate ligament transection (ACLT) alone or transection of both ACL and medial collateral ligament and partial resection of medial meniscus (ACLT $+\mathrm{MMx}$ ), total RNA extracted from the three tissue slices was found to have high quality and relatively consistent amounts between the collected individual joints. To minimize animal variability, six slices per group were combined for each time point. Total RNA isolated from the first slices containing both articular cartilage and subchondral bone was evaluated by real time PCR using known gene markers for cartilage and bone catabolism and anabolism (Table 2). It should be noted that the real time PCR data represented the averaged values from three independent time-course experiments.

In articular cartilage and subchondral bone slices (slice\#1), there were time-dependent and marked changes in the expression profiles of known cartilage degeneration genes in response to either ACLT or ACLT+MMx surgically induced joint instability, as compared to those in the contra-lateral left joints and Sham-operated joints (Figure 2A). However, there were only subtle differences in the profiles of these cartilage and bone makers in the epiphyseal (slice\#2) and metaphyseal (slice\#3) slices in the ACLT or ACLT+MMx joints as compared to the contra-lateral joints (Figure $2 \mathrm{~B}$ and data not shown). Therefore, in this study, we focused further analyses in slice 1 to study regulation of key markers (Table 2) for cartilage matrix degradation (aggrecanase-1, metalloproteinase-13 (MMP-13)), chondrocyte differentiation (collagen IIA and Sox 9), angiogenesis (VEGF, CD31, KDR), bone resorption (cathepsin $\mathrm{K}$ and tartrate resistant acid phosphatase (TRAP)) and bone formation (runx2, osterix, bone sialoprotein and osteopontin).

Early regulation of markers for matrix degradation in the articular cartilage and subchondral bone in the rat models of joint instability-induced osteoarthritis

The gene expression patterns during disease progression in the ACLT and ACLT+MMx models of joint instability versus Sham-operated animals were characterized by mRNA levels using real time PCR and confirmed by protein levels using immunohistochemical methods. Early changes evident in OA include surface cartilage damage and subchondral bone remodeling. As shown in Figure 2A, aggrecanase-1 and MMP-13, proteolytic enzymes which degrade the cartilage matrix, were upregulated as early as week 1 in both OA models as compared to Sham. Expression levels of aggrecanase-1 aggressively increased 3-4 fold in both ACLT+MMx and ACLT models, respectively, relative to Sham (Figure 2Aa; Table 2). The aggrecanase-1 mRNA expression levels 
Table 2 Summary of gene expression patterns regulated in joint-instability induced osteoarthritis progression in rats (slice\#1)

\begin{tabular}{|c|c|c|c|c|c|c|c|c|c|c|}
\hline \multirow{3}{*}{$\begin{array}{l}\text { Gene } \\
\text { Week post-surgery }\end{array}$} & \multirow{3}{*}{$\begin{array}{l}\text { ACLT } \\
1 \\
\end{array}$} & \multicolumn{9}{|c|}{$\mathrm{ACLT}+\mathrm{MMx}$} \\
\hline & & \multicolumn{9}{|c|}{ (Fold increase over Sham in articular cartilage/subchondral bone region) } \\
\hline & & 2 & 4 & 6 & 10 & 1 & 2 & 4 & 6 & 10 \\
\hline \multicolumn{11}{|l|}{ Matrix Degradation } \\
\hline Aggrecanase I & 4.3 & 2.1 & 2.5 & 1.6 & 2.6 & 4.2 & 1.7 & 2.9 & 2.3 & 3.2 \\
\hline MMP13 & 2.8 & 1.6 & 1.9 & 2.0 & 4.3 & 3.7 & 1.6 & 2.0 & 2.2 & 5.8 \\
\hline \multicolumn{11}{|c|}{ Chondrocyte differentiation } \\
\hline Collagen IIA & 2.3 & 2.0 & 2.8 & 1.3 & 1.3 & 1.8 & 1.5 & 2.2 & 1.4 & 1.2 \\
\hline Sox 9 & 2.6 & 1.8 & 1.4 & 1.4 & 0.8 & 1.8 & 1.1 & 1.4 & 1.8 & 1.4 \\
\hline \multicolumn{11}{|l|}{ Angiogenesis } \\
\hline VEGF & 1.3 & 2.1 & 1.6 & 1.8 & 1.1 & 1.7 & 1.3 & 1.8 & 1.3 & 1.6 \\
\hline CD31 & 2.1 & 3.1 & 1.6 & 1.8 & 1.4 & 2.2 & 2.0 & 1.9 & 1.4 & 2.3 \\
\hline KDR & 1.3 & 3.2 & 1.3 & 1.3 & 1.1 & 1.4 & 2.2 & 1.3 & 1.2 & 1.3 \\
\hline \multicolumn{11}{|l|}{ Bone resorption } \\
\hline Cathepsin K & 1.5 & 1.5 & 1.8 & 2.7 & 2.5 & 1.8 & 1.9 & 2.1 & 2.0 & 4.1 \\
\hline \multicolumn{11}{|l|}{ TRAP } \\
\hline \multicolumn{11}{|l|}{ Bone formation } \\
\hline Runx2/cbfa-1 & 0.7 & 1.0 & 1.1 & 1.8 & 1.2 & 0.9 & 0.9 & 1.5 & 1.8 & 2.0 \\
\hline Osterix & 0.7 & 0.9 & 1.0 & 1.7 & 1.1 & 1.2 & 0.9 & 1.6 & 1.6 & 1.6 \\
\hline Bone sialoprotein & 1.1 & 1.4 & 1.7 & 1.8 & 1.6 & 1.6 & 1.3 & 1.5 & 1.9 & 2.9 \\
\hline Osteopontin & 1.3 & 1.3 & 1.9 & 1.5 & 1.8 & 1.7 & 1.1 & 1.8 & 2.4 & 4.1 \\
\hline
\end{tabular}

remained elevated at a high steady-state above Sham up to 10 -week post-surgery, supporting the relevant role of this enzyme in cartilage degeneration during the initial and progressive phases of $\mathrm{OA}$.

The regulation of MMP-13 synthesis was similar, yet more modest, to that of aggrecanase-1 in ACLT and ACLT+MMx joints. MMP13 expression levels in the transected joints were elevated by $\sim 2$ - fold as early as week 1, relative to Sham and remained elevated relative to Sham peaking at 3-5 fold by week 10 (Figure 2A-b; Table 2). Remarkably, regulation of these two enzyme markers was specific to the diseased joint as their respective levels were not different in contra-lateral intact joints (left), relative to Sham-operated joints (Figure 2A-c, 2d). Furthermore, there were no changes in aggrecanase-1 (data not shown) or in MMP-13 mRNA levels (Figure 2B-a, 2b) detected in deeper epiphyseal and metaphyseal bone tissue layers (slices 2 \& 3 ) in any treatment group.

Immunohistochemical staining of the frontal section of the medial tibeal plateau and growth plate demonstrated sustained MMP-13 expression as shown in Figure $2 \mathrm{C}$. In the ACLT $+\mathrm{MMx}$ model, protein levels of MMP-13 were apparent in the differentiated chondrocytes and synovial cells of the cartilage surface (Figure $2 \mathrm{C}$-a) at 2 weeks following surgery. There was low, but detectable MMP-13 protein levels evident in the Sham articular cartilage, i.e. in a few cells in the deep zone (Figure 2C-b). At week 10 post-surgery, significant cartilage thinning and fraying, accompanied with advancement of subchondral bone and osteophyte formation (Figure 2C-c, arrowheads) were readily detected as a late stage event of OA progression. Osteochondral progenitors within the osteophyte region showed high levels of MMP-13 protein expression (Figure 2C-d with inset and Figure 2C-e, shown at high magnification of inset) within proximity to areas of vascular invasion. As a positive control, we stained for MMP-13 proteins known to be highly expressed in hypertrophic chondrocytes in the epiphyseal bone and growth plate (slice 2) of the ACLT+MMx joints in rats (Figure 2C-f). Similar to the results obtained from the real time PCR study, MMP-13 expression levels although expressed in high abundance, were not regulated in tissue slice 2 in response to ACLT or ACLT $+M M x$ as compared to Sham or contra-lateral intact joints (Figure $2 \mathrm{~B}$ ).

\section{Temporal regulation of gene markers for chondrocyte differentiation in the rat models of osteoarthritis}

Evidence has been presented suggesting that phenotypic alteration in articular chondrocytes is a facet of disease progression in OA [18]. Chondrocyte differentiation has been demonstrated to be an early event in disease progression with increased expression of collagen IIA (Col IIA), a splice variant normally expressed in chondroprogenitor cells during embryonic development [19]. Here, the ACLT model showed a 2-fold increase in Col IIA, relative to Sham at week 1 , peaked at 3 -fold through 

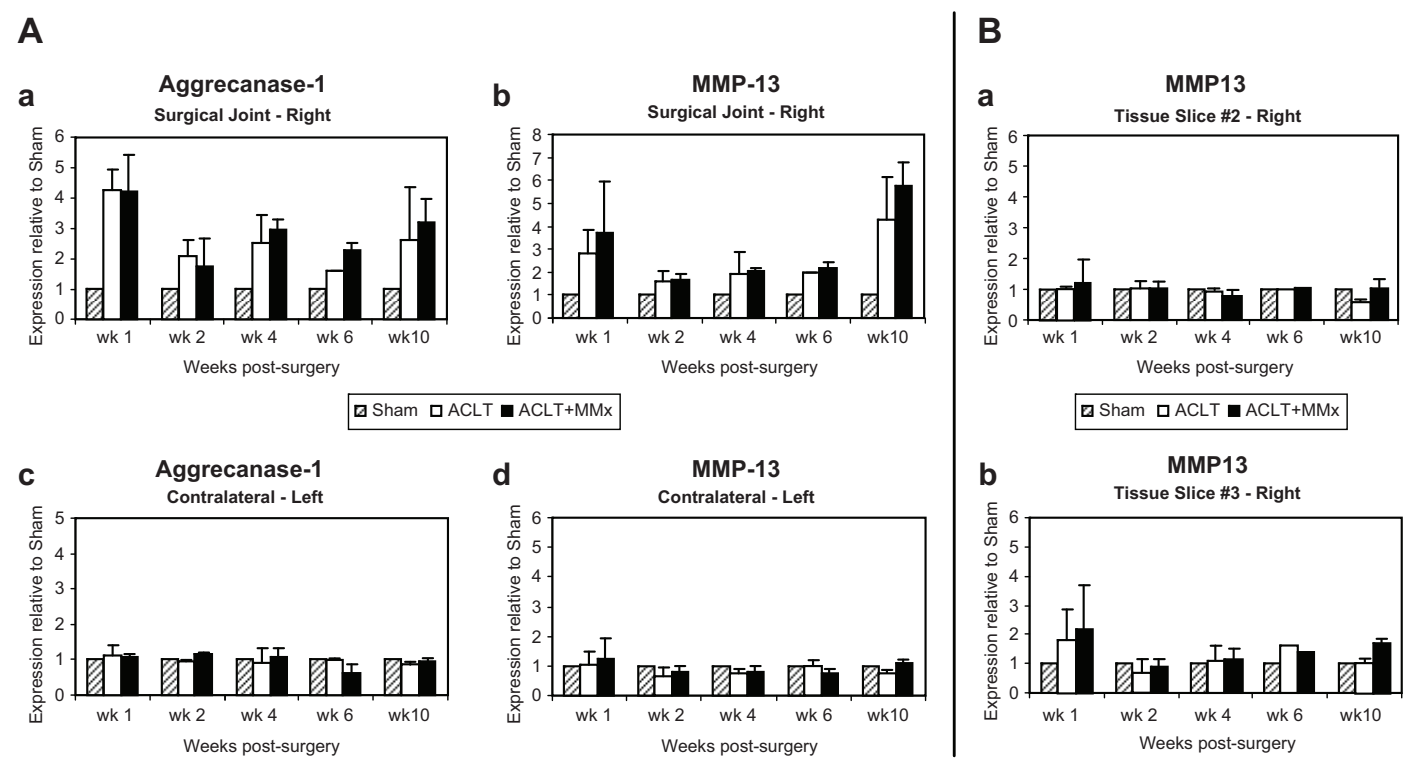

C
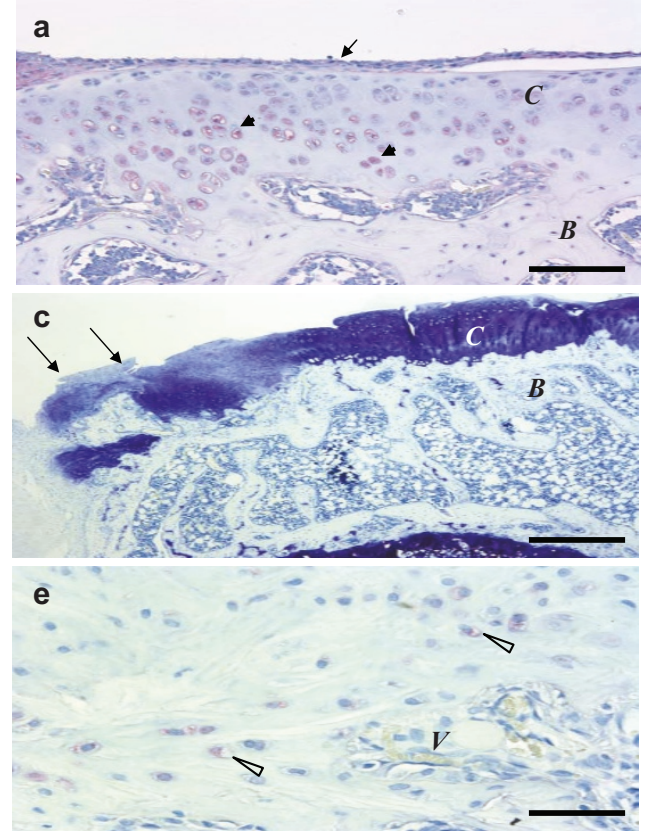
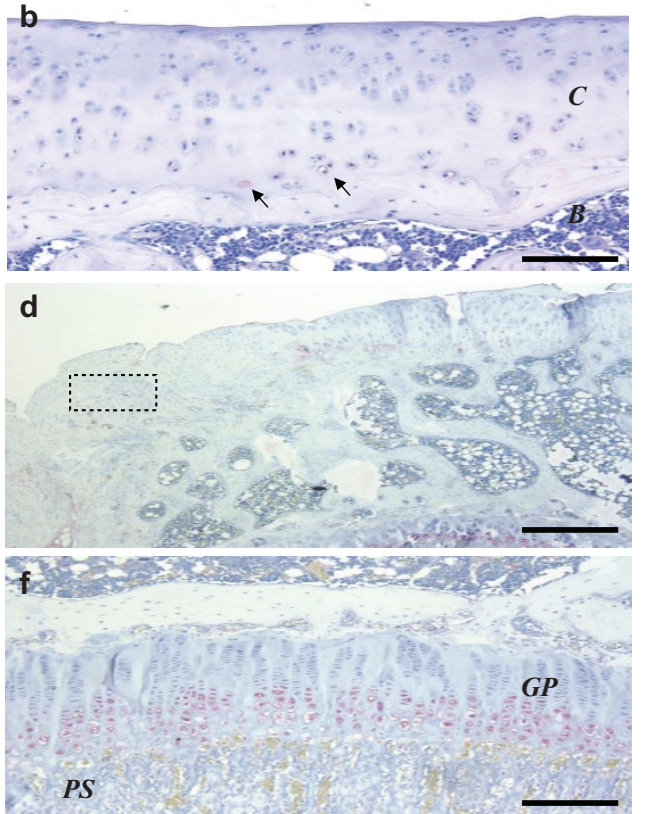

Figure 2 Up-regulation of matrix degradation markers as an early gene regulation event in the surgically-induced models of osteoarthritis. (A) Up-regulation of matrix degradation markers was seen as early as one week following surgery. (a) Aggrecanase-1 demonstrated early increases of 3-4 fold in ACLT+MMx and ACLT models, respectively. High levels of expression were maintained throughout the 10 wks of study duration. (b) MMP-13 levels were elevated 2-fold at wk 1 post-surgery. Levels progressively increased by 3 to 5 -fold relative to Sham through wk 10. (c, d) Expression levels of both markers were unaffected in contra-lateral joints over entire time course. (B) No changes in MMP-13 mRNA expression were observed in deep tissue slice 2 (a) or slice 3 (b). Similar results were observed for aggrecanase-1. All values are shown as mean $\pm S D$. (C) Frontal section of medial tibial plateau and growth plate were stained with anti-MMP-13 (a, b, d, e, and f) or toluidine blue-O (c). Articular cartilage, including growth plate, at wk 2 (a and b) and at wk 10 (c, d, e, and f) post-surgery are shown. (a) ACLT +MMx OA joint highly expressed MMP-13 in differentiated chondrocytes (closed arrowheads) and synovial cells on cartilage surface (arrow). (b) In sham joint, few cells are MMP-13 positive in deep zone (arrows). (c) Arrows indicate osteophyte formation in periarticular region of the medial tibial plateau of ACLT-MMx. (d) MMP-13 immunostaining of semi-serial section of (c). (e) Higher magnification of osteophyte region (inset in d) shows many MMP-13 positive chondrocytes are found in proximity to vascular invasion (open arrowheads). (f) In growth plate, as a positive control, MMP-13 was intensely stained in hypertrophic chondrocytes. C: articular cartilage. B: bone. V: vascular invasion. GP: growth plate. PS: primary spongiosa. Bar $=100 \mu \mathrm{m}$ in (a, b), $500 \mu \mathrm{m}(\mathrm{c}, \mathrm{d}), 50 \mu \mathrm{m}(\mathrm{e}), 200 \mu \mathrm{m}(\mathrm{f})$. 
weeks 2 and 4 and returned to Sham level in week 6 to 10 (Figure 3A; Table 2). Upregulation of Col IIA was also seen in the ACLT+MMx model, rising steadily to a maximum of 2-fold at 4-week post-surgery, and subsequently returned to Sham levels during the later stage of disease progression (Figure 3A; Table 2). We also investigated the temporal regulation of Sox 9, a marker for chondrocyte differentiation. Similar to the Col IIA expression pattern, Sox 9 expression was upregulated in ACLT-joints as early as week 1 , followed by a progressive return to baseline levels by week 10 (Figure 3B; Table 2). Although the ACLT+MMx model has been characterized to have more aggressive disease progression, the levels of Col IIA and Sox 9 regulation were lower than those in the ACLT model at weeks 1 and 2 (Figure 3B, Table 2).
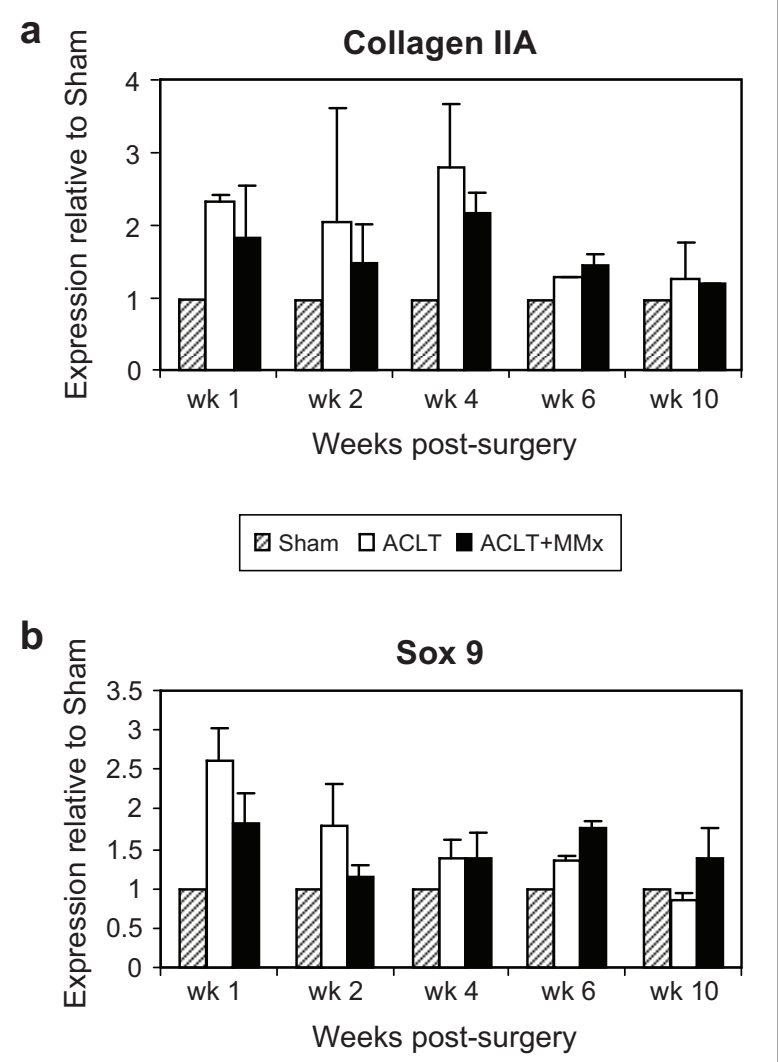

Figure 3 Temporal regulation of markers of chondrocyte differentiation in the surgically-induced models of $O A$. (A) Collagen IIA was increased by 2 -fold in ACLT model at wk 1 relative to Sham. Expression levels peaked at 3-fold through wk 2 and 4 and returned to Sham levels in wk 6 and 10. (B) Sox 9

demonstrated a similar, those less striking pattern of expression. Sox 9 was upregulated at wk 1 in ACLT and returned to Sham levels in wk 6 and 10. The fold changes in Col IIA levels were significantly lower in ACLT+MMx as compared to those in ACLT model. All values are shown as mean $\pm S D$
Temporal regulation of gene markers for angiogenesis in the rat models of osteoarthritis

Vascular invasion into calcified cartilage is obligatory in normal endochondral bone formation and has also been demonstrated to occur during disease progression in experimental models of OA. We examined the timedependent regulation of typical gene markers for angiogenesis in tissue slice \#1, containing articular cartilage and subchondral bone. The angiogenesis marker, VEGF, was up-regulated approximately 2 fold at week 2 and week 4, in ACLT and ACLT-MM respectively, responding to joint instability in both surgically-induced models, (Figure 4A; Table 2). Expression remained elevated relative to Sham in both models through week 6. As shown in Table 2, we also examined the regulation profiles of two other angiogenic markers including CD31 and the VEGF receptor, KDR. Similar to the regulation pattern of VEGF, both CD31 and KDR were highly upregulated at week 2 , by $\sim 3$-fold in the ACLT joints and by $\sim 2$-fold in the ACLT+MMx joints (Table 2). Expression of these two vascular markers returned towards Sham levels by week 10 in the ACLT joints, yet remained slightly elevated above Sham levels up to week 10 post-surgery (Table 2). in ACLT-MMx joints.

Vascular invasion as an early event in ACLT and ACLT+MMx joints was further confirmed using immunohistochemistry. From representative thin sections isolated from an ACLT+MMx joint at week 2 post-surgery, the number of VEGF-positive (blue) hypertrophic chondrocyte-like cells significantly increased in the deep articular cartilage layer, adjacent to subchondral bone (arrowheads, Figure 4B-a, and inset shown in b). In proximity to the VEGF-positive chondrocytes, we detected vascularized structures positive for KDR (brown) invading the calcified deep cartilage layer (arrows, Figure 4B-b). In the Sham joint, very few VEGF-positive stained cells were detected in the deep zone of articular cartilage (arrow-heads, Figure 4B-c). However, KDR-positive signals could be readily detected in vascular endothelial cells in the bone marrow of the epiphysis, distant from VEGF (arrows, Figure 4B-c).

\section{Progressive increases in gene markers for bone remodeling in the rat models of osteoarthritis} In addition to cartilage degeneration, subchondral bone remodeling and osteophytosis are notable events during the disease progression in both of the surgically-induced models in rats. We previously documented early involvement of subchondral osteopenia, which was followed by subchondral sclerosis in response to joint instability in both ACLT and ACLT+MMx models of OA in rats. Hence, time dependent regulation of subchondral bone loss was assessed by two different gene markers specific for osteoclastic bone resorption, CatK and tartrate 

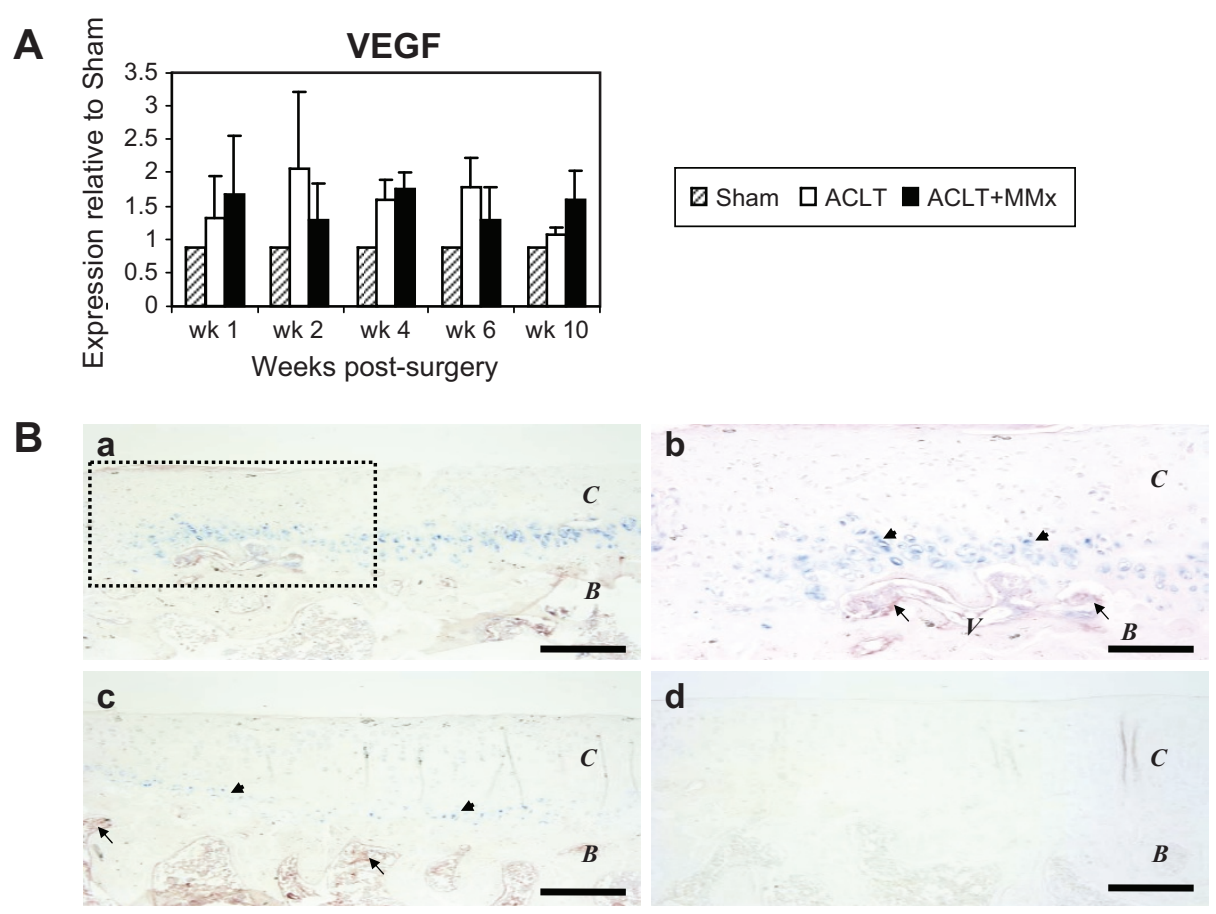

Figure 4 Up-regulation of markers of angiogenesis in the surgically-induced models of joint instability. (A) Induction of angiogenesis gene expression marker, VEGF, was seen at 2-wk post-surgery in both models. Levels of VEGF increased approximately 2 fold at week 2 , maintained expression during wk 4 and 6 and returned to Sham levels by week 10. All values are shown as mean \pm SD. (B) Frontal section of medial tibial plateau and growth plate were stained with anti-VEGF (blue) and anti-KDR (brown). (a) At 2-wk post-surgery, many chondrocytes differentiated to hypertrophic chondrocytes in ACLT+MMx joint. (b) Higher magnification of inset in (a) showed that hypertrophic chondrocytelike cells strongly stained with VEGF (arrowheads). KDR (brown) positive cells are found in proximity with VEGF-positive cells (arrow). (c) Sham joint shows a few VEGF-positive cells in deep zone of articular cartilage (arrowheads). Vascular endothelial cells are positive for KDR in bone marrow, but not in proximity with VEGF-positive cells (arrows). (d) Negative control shows no specific staining. C: articular cartilage. B: bone. V: vascular invasion. $\mathrm{Bar}=200 \mu \mathrm{m}$ in ( $\mathrm{a}, \mathrm{c}$ and $\mathrm{d})$; and $100 \mu \mathrm{m}$ in (b).

resistant acid phosphatase (TRAP) using real-time PCR of tissue slice \#1. Expression of mRNA levels of CatK was elevated (1.5 to 2 -fold) as early as week 2 post-surgery, then steadily increased to maximal expression $(\sim 2$ to 4-fold) at week 10 in the ACLT and ACLT+MMx models, respectively (Figure 5A-a). The pattern of time dependent regulation of TRAP was similar to that of CatK (Figure 5A-b), reconfirming these are selective markers for mature osteoclasts.

The levels of CatK (brown) and MMP-9 (red) were costained using immunohistochemical methods with paraffin embedded sections from typical ACLT+MMx joints versus Sham joints at week-2 post-surgery (Figure 5B). At 2 weeks post surgery irregular articular surface was observed in the OA-joints (arrow, Figure 5B-a). In the articular cartilage and subchondral regions, CatK expression was detected in multinucleated osteoclast-like cells invading into the deep calcified cartilage layer as an early event in this surgically-induced model (arrowheads, Figure 5B-a, and inset shown in b). Interestingly, MMP-9positive signal (red) was only localized in the extracellular matrix adjacent to hypertrophic chondrocytes specifically in proximity to the invading osteoclasts (open arrowhead, Figure 5B-b). There was no MMP-9 expression detected in the vicinity of the multinucleated osteoclasts on subchondral bone surfaces (arrowheads, Figure 5B-a). A similar pattern of MMP-9 expression in hypertrophic chondrocytes in proximity to osteoclasts was found at the border of the growth plate and the mineralized primary spongiosa (Figure 5B-d). As control, CatK and MMP-9 were localized to osteoclasts in the subchondral bone plate of the Sham-joints. No detectable CatK/ MMP-9 positive cells were observed to have invaded the Sham articular cartilage (data not shown).

Subchondral sclerosis and osteophyte formation occur late in the disease progression in these experimental models of OA. Two transcription factors, Runx $2 / \mathrm{Cbfa} 1$ and osterix, have been shown to play critical roles in mediating bone anabolism. Runx2 plays the rate-limiting role in regulating bone formation, and also regulates osterix during osteoblast differentiation [20]. Neither runx2 nor osterix increased until the late stages (up to 
A
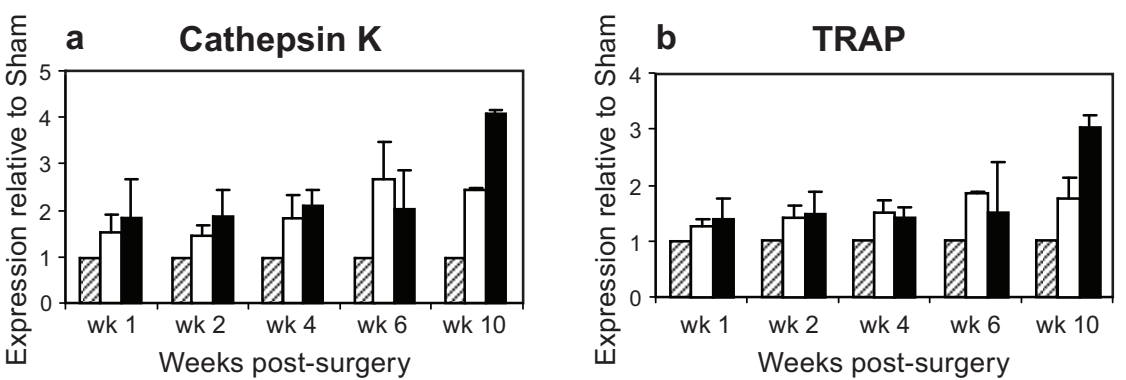

V Sham $\square$ ACLT $\square \mathrm{ACLT}+\mathrm{MMx}$

B
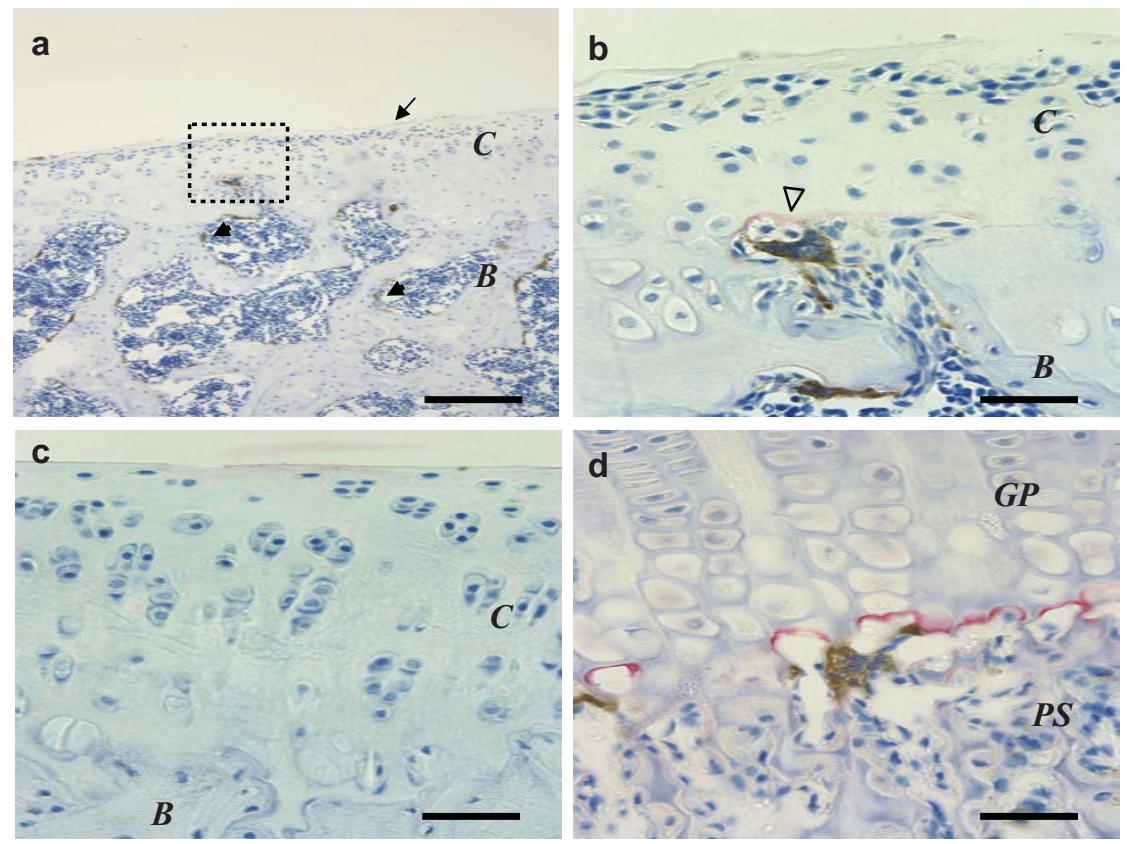

Figure 5 Bone resorption markers are increased in rat models of OA. (A) Up-regulated expression of Cat K and TRAP (a) Cat K levels progressively increased by 2 to 4 -fold in ACLT and ACLT-MMx, respectively, versus Sham. (b) Similarly, time-dependent upregulation of TRAP expression peaked at 2 to 3 fold in ACLT and ACLT-MMx, respectively. All values are shown as mean \pm SD. (B) Immunolocalization of osteoclastic markers (MMP-9 and Cat K) in ACLT-MMx joint at 2-wk after surgery. (a-d) Frontal section of medial tibial plateau and growth plate were stained with anti-Cat K (brown) and anti-MMP-9 (red). (a) At 2-wk post-surgery, irregular articular surface is observed (arrow). Cat K positive

multinucleated cells detected on trabecular bone surface in bone marrow (arrowheads). (b) Cat K positive cells invading into articular cartilage are found in proximity to MMP-9 (red) staining (open arrowhead) with higher magnification of squared area in (a). (c) Negative control shows no specific staining. (d) Growth plate and primary spongiosa, stained as positive control, demonstrated Cat K positive cells in proximity to MMP-9 stained region in the border of cartilage and primary spongiosa. C: articular cartilage. B: bone. GP: growth plate. PS: primary spongiosa. Bar $=500$ $\mu \mathrm{m}$ in $(\mathrm{a}, \mathrm{c}) ; 50 \mu \mathrm{m}$ in $(\mathrm{b}, \mathrm{d})$.

2-fold at week 4 to 6) of disease progression in ACLT $+\mathrm{MMx}$ and ACLT models, respectively (Figure 6-a, b, Table-2). Similar regulation patterns were also seen with bone sialoprotein and osteopontin in these surgicallyinduced models of OA (Table 2).

\section{Discussion}

Accumulating evidence supports the hypothesis that subchondral bone remodeling in $\mathrm{OA}$ is a major contributing factor to this degenerative disease [21]. The integrity of articular cartilage depends on the mechanical as well as biochemical properties of the underlying bone [21,22]. In spontaneous OA animal models and in OA patients, density and metabolism of the subchondral bone have been suggested to occur prior to detectable signs of cartilage damage [22-26]. We have previously shown in the ACLT and ACLT+MMx models of OA in rats, histological evidence demonstrating that joint 


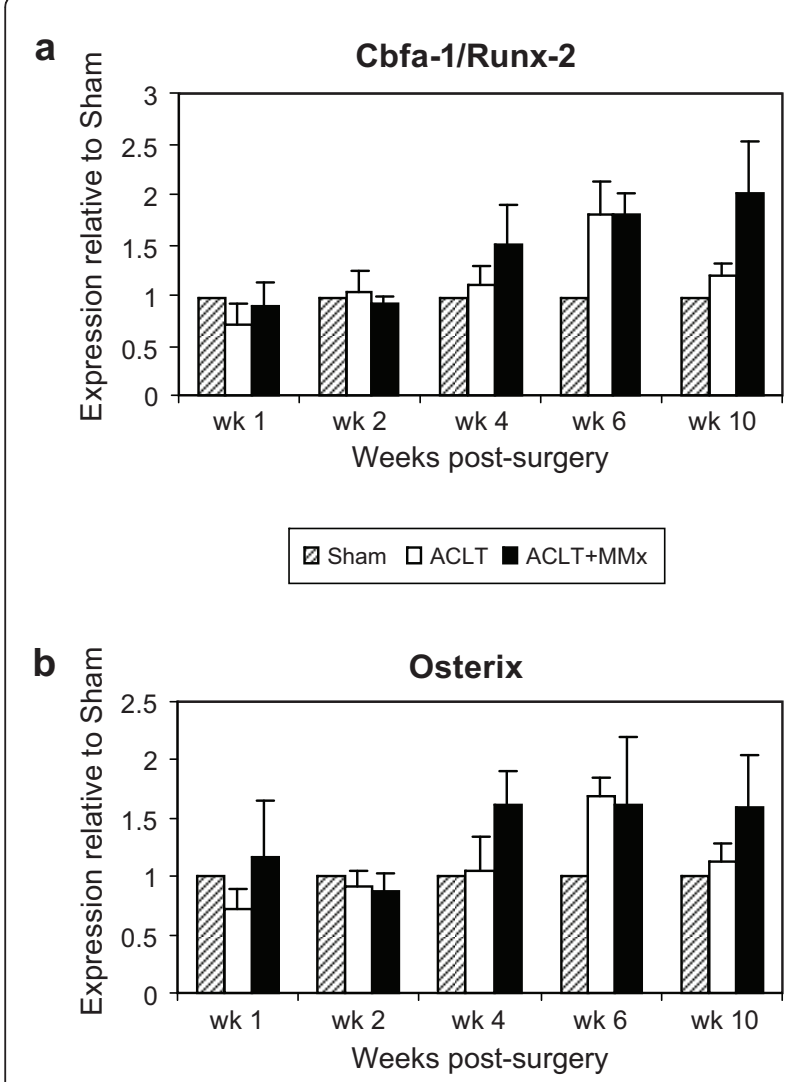

Figure 6 Up-regulation of transcription factors mediating bone anabolism, runx2 and osterix in the rat surgical models of $O A$. Bone formation marker runx2 (a) and its downstream target osterix (b) were up-regulated during the later stage of disease progression in ACLT+MMx by $\sim 2$-fold in wk 4 post-surgery, and in ACLT by 2 -fold in wk 6 post-surgery relative to Sham. All values are shown as mean $\pm S D$

instability also accelerated subchondral remodeling, occurring concomitantly and in proximity to surface cartilage damage in early stage OA [16]. As the disease advances, in OA animal models significant cartilage thinning, subchondral bone sclerosis and osteophyte formation has been observed [15,27-29].

To understand the molecular mechanisms of cartilage degeneration and subchondral bone sclerosis and the potentially coordinated signals between the two tissues during OA progression, we developed a fast and uniform approach to collect together the articular cartilage and subchondral bone tissues from the tibia of the ACLT and ACLT+MMx models of OA in rats. Prior to performing extensive genome-wide profiling of gene expression and pathway analyses in these models, we described here the validation of this approach by demonstrating the time-dependent and sequential changes in these tissues using real-time PCR and confirmation with immunohistochemical methods for genes previously demonstrated to be involved in the pathogenesis of OA.

Previous studies have evaluated gene expression in vivo either by means of global profiling, or by studying subsets of collagenases or cytokines in articular cartilage in similar experimental models of OA [30-33]. These studies demonstrated that the gene expression changes during the disease progression in animal models of OA mimic that in human. Experimental models of OA provided important insights on key signaling pathway(s) that involved proteases, cytokines or growth factors in mediating OA pathogenesis. However, these early studies were primarily restricted to examining molecular changes in the cartilage layer, without integrating information from the pre-articular subchondral bone in response to the surgically-induced joint instability. Furthermore, these studies employed collection of articular cartilage from the small joints of the rodent $[34,35]$, by pooling pieces of cartilage tissues shaved from the bone surface. This method often results in high variability in the amount and quality of RNA collected from the joints. We sought to reduce this variability and investigate bone in addition to cartilage by systematically collecting the tibial plateau slice containing both articular cartilage and the underlying subchondral bone. Variability was further reduced by combining slices from each cut within a group, and performing replicate time-course studies. Expression levels of each RNA pool were compared to expression levels from sham operated joints for each independent study increasing the confidence of gene expression changes demonstrated. It should be noted that this does limit the ability to detect animal specific changes within a group. Also, inherent variability in biological models is reflected in the degree of fold change demonstrated, thus error bars are large in some instances although the direction of change was always consistent. The reduction in the time of tissue collection by using serially collected bone slices yields an additional advantage. Thus, this method has potential application for high-throughput collection of tibial plateaux tissues involved in OA pathogenesis.

While our method has the advantage of consistently sampling RNA for a global assessment of the joint tissues, we recognize the approaches limitation to evaluate the specific changes in bone or articular cartilage, due to the common expression of many genes in both chondrocytes and osteoblasts. On the other hand, to support the long-term genome-wide profiling efforts to increase our understanding of the pathogenesis of the degenerative joints in response to mechanical instability, we have collected the combined subchondral bone and articular cartilage from the spontaneous STR/ort mice [36] and the surgically induced rat models. In addition, we have 
also collected separately the articular cartilage layer and the subchondral bone from the ACLT-dogs and from the humans with primary OA for array studies. By integrating information for gene pathway analyses on these tissues from multiple species, we believe this will provide a comprehensive approach to identify novel mechanism(s) involved at multiple tissue levels during OA progression.

Early degenerative changes have been reported in the superficial zone of articular cartilage in both models and consisted of proteoglycan loss and detectable surface collagen damage, accompanied by increased chondrocyte proliferation and hypertrophy within 2 weeks of surgery $[16,31,37,38]$. Preceding the histological changes in the ACLT and ACLT+MMx joints, we showed that the expression patterns of MMP-13 and aggrecanase-1, responsible for degradation of collagen type II and of proteoglycan core proteins, respectively, were quickly and significantly up-regulated as early as the first week post-surgery. Interestingly, expression of these proteases remained significantly elevated above basal levels during the 10 week study, confirming the important roles of these enzymes in the continuous break down of tissues within the joint as the disease progresses [39-41].

The onset of chondrogenic differentiation has been confirmed by the appearance of glycosaminoglycan, aggrecan and Col IIA, a splice variant of the Col II gene, expression by chondroprogenitors in the extracellular matrix [42]. The transcription factor Sox 9 is required for mesenchymal condensation. Together with Sox 5 and Sox 6, Sox 9 mediates chondrocyte differentiation and expression of a series of chondrocyte-specific marker genes including Col2a1, Col9a2, Col11a2 and aggrecan [43]. Activation of Sox 9 is also important for endochondral bone formation. In our hands, within the first week post-surgery, gene markers for chondrocyte differentiation, Col IIA and Sox 9, were highly upregulated. However, unlike the markers of matrix degradation, expression levels of Col IIA declined by week 6 post-surgery, while Sox 9 was significantly reduced by week 2 post-surgery. This finding may support the hypothesis that early chondrocyte differentiation in response to joint instability is an attempt to repair the tissue during the early phase of disease progression [19]. Mesenchymal condensation and chondrocyte differentiation have been implicated in the early stages of osteophyte formation [44] and potentially, this upregulation of Sox 9 and Col IIA may reflect the initial commitment of the osteochondral progenitors to the development of osteophytes in ACLT and ACLT+MMx models.

Normal adult articular cartilage remains avascular. Vascularization of the articular cartilage, preceding subchondral remodeling and osteophytosis, is a hallmark of the pathology of OA [45]. Previously, in the ACLT and
ACLT+MMx model, vascular invasion into the calcified deep layer of articular cartilage could be detected as early as 2 weeks post-surgery [16]. Here, significantly increased expression of the angiogenic factor VEGF was detected at week 2 and remained elevated up to week 6 post-surgery in both models as compared to Sham. Similar to VEGF, the expression profile of its receptor, $\mathrm{KDR}$, and the endothelial marker, CD31, were highly upregulated at 2 weeks post-surgery. Interestingly, in the osteochondral junction of the surgically-induced joints, the CD31-positive blood vessels were frequently found to be in proximity of the chondrocytes expressing VEGF, suggesting early vascular invasion into cartilage may lead to focal endochondral bone formation, and subsequently to subchondral bone remodeling. This process may eventually promote osteophytosis at the late stage of disease progression. All immunohistochemical observations are consistent with our previous histological survey on vascularization in these rat models of OA [17].

As determined by histological evaluation, vascular invasion into calcified cartilage at the osteochondral junction was almost always found together with the presence of osteoclasts, and preceded subchondral bone sclerosis. We have reported previously in the ACLT and ACLT + MMx models of OA, that subchondral osteopenia was significant $\sim 2$ weeks post-surgery, soon after the initially observed focal surface cartilage damage and in absence of marked cartilage thinning [16]. Indeed, the bisphosphonate alendronate was demonstrated to retard the disease progression in the ACLT model of OA in rats [46]. Even though multinucleated osteoclasts represent a very small fraction of the total cellular contents in cartilage and bone tissues, upregulation (1.5 to 2-fold) of osteoclast-specific markers, CatK and TRAP, was readily detected in ACLT and ACLT+MMx joints as early as 2 weeks post-surgery. This observation coupled to subsequent subchondral bone remodeling may explain the progressive elevation of these two markers in the articular cartilage and subchondral bone slice in the OA joints.

Changes in subchondral bone are believed to occur in the later stage of OA, particularly osteophytosis. While runx $2 /$ cbfa- 1 is also expressed in hypertrophic chondrocytes, this transcription factor is the master gene of bone formation [47]. Osterix is a runx 2 dependent osteoblast transcription factor, required for bone formation. Expression of runx2 and osterix together is fundamental for mesenchymal commitment to osteogenesis. In addition to runx 2 and osterix, we also determined the regulation of two preferential matrix markers for osteoblasts, bone sialoprotein and osteopontin. We demonstrated that regulation profiles of the transcription factors runx 2 and osterix, as well as osteogenic 
matrix proteins, were initiated at week 4 and maximal by 6 week post-surgery; thus supporting previous histological findings demonstrating a significant increase in subchondral bone sclerosis and osteophyte formation toward the later stages of disease progression in these two surgical models of OA [16]. Different from other markers associated with cartilage changes, the degree of change of the bone remodeling genes appeared to be more severe in the ACLT+MMx relative to that in the ACLT model. This is in agreement with previous histological findings [16] where osteophyte development in ACLT+MMx model was found to be more severe than that in ACLT model at week 6 and 10 post-surgery.

\section{Conclusion}

In summary, articular degeneration and bone sclerosis are the most consistently observed characteristics of osteoarthritis (OA). The surgically-induced joint instability models of $\mathrm{OA}$ in rats, which resemble posttraumatic OA in humans, are useful tools to study OA pathogenesis. To evaluate the potential coordinating molecular mechanisms of cartilage degeneration and subchondral bone remodeling during disease progression, we developed a consistent and reliable method to harvest both articular cartilage and subchondral bone from the tibial plateaux of the surgically-induced joint instability models of $\mathrm{OA}$ in rats. Here, we described the validation of this approach by demonstrating the timedependent and sequential changes in gene expression profiles of key markers for cartilage degradation, chondrocyte differentiation, vascular invasion and bone remodeling in these tissues using real-time PCR and confirmation with immunohistochemical methods. From the experimental models and humans with OA, rich sources of published information on the key pathways regulated in the articular cartilage and synovium are available $[48,49]$. However, the same type of information for the subchondral bone is still lacking. To gain further understanding of the sequential and cohesive regulation of complex and potential novel biological pathways in the joints during disease progression, the findings in this study have focused our future efforts on genome-wide profiling of gene expression and pathway analyses of the subchondral cartilage and bone. Integrated information on gene profiling of the subchondral bone during OA progression will be analyzed by cross referencing the results from the combined tissues to existing published articular cartilage databases.

\section{Acknowledgements}

We thank P. Rebbeck, J. Destafano and LAR staff for help with surgical procedures, and S. Hill and B. Connolly for advice on histological methods. We would like to thank Dr. Boyd B. Scott Ph.D. for assistance in the preparation of this manuscript.
Funding

This study was funded by Merck Sharpe \& Dohme, a subsidiary of Merck \& Co., Inc.

\section{Authors' contributions}

MP, TH and LD designed and executed the animal study design, in vivo OA surgery, the development of tissue collection methods and the study necropsy. MP carried out all RNA collection, real-time PCR experiments and subsequent analyses. TH and $Y Z$ carried out immunohistochemical methods. MP, TH and LD helped to draft the manuscript. All authors read and approved the final manuscript.

\section{Competing interests}

Maureen Pickarski, Ya Zhuo, and Le T. Duong are employees of Merck, the studies' sponsor, and may own stock/stock options in the company. Tadashi Hayami was an employee of Merck during the conduct of these studies and the preparation of this manuscript.

Received: 2 March 2011 Accepted: 24 August 2011

Published: 24 August 2011

\section{References}

1. Lohmander LS: What can we do about osteoarthritis? Arthritis Res 2000, 2:95-100.

2. Oettmeier R, Abendroth $\mathrm{K}$, Oettmeier $\mathrm{S}$ : Analyses of the tidemark on human femoral heads. II. Tidemark changes in osteoarthrosis-a histological and histomorphometric study in non-decalcified preparations. Acta Morphol Hung 1989, 37:169-180.

3. Haywood L, McWilliams DF, Pearson Cl, Gill SE, Ganesan A, Wilson D, Walsh DA: Inflammation and angiogenesis in osteoarthritis. Arthritis Rheum 2003, 48:2173-2177.

4. Radin EL, Rose RM: Role of subchondral bone in the initiation and progression of cartilage damage. Clin Orthop Relat Res 1986, 34-40.

5. Hutton CW, Higgs ER, Jackson PC, Watt I, Dieppe PA: 99mTc HMDP bone scanning in generalised nodal osteoarthritis. II. The four hour bone scan image predicts radiographic change. Ann Rheum Dis 1986, 45:622-626.

6. Burr DB: The importance of subchondral bone in osteoarthrosis. Curr Opin Rheumatol 1998, 10:256-262.

7. Goker B, Sumner DR, Hurwitz DE, Block JA: Bone mineral density varies as a function of the rate of joint space narrowing in the hip. $J$ Rheumatol 2000, 27:735-738.

8. Pastoureau P, Leduc S, Chomel A, De Ceuninck F: Quantitative assessment of articular cartilage and subchondral bone histology in the meniscectomized guinea pig model of osteoarthritis. Osteoarthritis Cartilage 2003, 11:412-423.

9. Pelletier JP, Boileau C, Brunet J, Boily M, Lajeunesse D, Reboul P, Laufer S, Martel-Pelletier J: The inhibition of subchondral bone resorption in the early phase of experimental dog osteoarthritis by licofelone is associated with a reduction in the synthesis of MMP-13 and cathepsin K. Bone 2004, 34:527-538.

10. Bettica P, Cline G, Hart DJ, Meyer J, Spector TD: Evidence for increased bone resorption in patients with progressive knee osteoarthritis: longitudinal results from the Chingford study. Arthritis Rheum 2002, 46:3178-3184.

11. Hunter DJ, Spector TD: The role of bone metabolism in osteoarthritis. Curr Rheumatol Rep 2003, 5:15-19.

12. Lane NE, Nevitt MC: Osteoarthritis, bone mass, and fractures: how are they related? Arthritis Rheum 2002, 46:1-4.

13. Qvist P, Christiansen C, Karsdal MA, Madsen SH, Sondergaard BC, BayJensen AC: Application of biochemical markers in development of drugs for treatment of osteoarthritis. Biomarkers 2010, 15:1-19.

14. Kraus VB, Burnett B, Coindreau J, Cottrell S, Eyre D, Gendreau M, Gardiner J, Garnero P, Hardin J, Henrotin Y, Heinegard D, Ko A, Lohmander LS, Matthews G, Menetski J, Moskowitz R, Persiani S, Poole AR, Rousseau JC, Todman M: Application of biomarkers in the development of drugs intended for the treatment of osteoarthritis. Osteoarthritis Cartilage 2011, 19:515-542.

15. Bendele AM: Animal models of osteoarthritis. J Musculoskelet Neuronal Interact 2001, 1:363-376.

16. Hayami T, Pickarski M, Zhuo Y, Wesolowski GA, Rodan GA, Duong IT: Characterization of articular cartilage and subchondral bone changes in 
the rat anterior cruciate ligament transection and meniscectomized models of osteoarthritis. Bone 2006, 38:234-243.

17. Hayami T, Funaki H, Yaoeda K, Mitui K, Yamagiwa H, Tokunaga K, Hatano H, Kondo J, Hiraki Y, Yamamoto T, Duong IT, Endo N: Expression of the cartilage derived anti-angiogenic factor chondromodulin-I decreases in the early stage of experimental osteoarthritis. J Rheumatol 2003, 30:2207-2217.

18. Salminen H, Vuorio E, Saamanen AM: Expression of Sox9 and type IIA procollagen during attempted repair of articular cartilage damage in a transgenic mouse model of osteoarthritis. Arthritis Rheum 2001, 44:947-955.

19. Aigner T, Zhu Y, Chansky HH, Matsen FA, Maloney WJ, Sandell L: Reexpression of type IIA procollagen by adult articular chondrocytes in osteoarthritic cartilage. Arthritis Rheum 1999, 42:1443-1450.

20. Nishio Y, Dong Y, Paris M, O'Keefe RJ, Schwarz EM, Drissi H: Runx2mediated regulation of the zinc finger Osterix/Sp7 gene. Gene 2006, 372:62-70

21. Dequeker J: The inverse relationship between osteoporosis and osteoarthritis. Adv Exp Med Biol 1999, 455:419-422.

22. Ameye $L G$, Young MF: Animal models of osteoarthritis: lessons learned while seeking the "Holy Grail". Curr Opin Rheumatol 2006, 18:537-547.

23. Grynpas MD, Alpert B, Katz I, Lieberman I, Pritzker KP: Subchondral bone in osteoarthritis. Calcif Tissue Int 1991, 49:20-26.

24. Li B, Aspden RM: Composition and mechanical properties of cancellous bone from the femoral head of patients with osteoporosis or osteoarthritis. J Bone Miner Res 1997, 12:641-651.

25. Mansell JP, Tarlton JF, Bailey AJ: Biochemical evidence for altered subchondral bone collagen metabolism in osteoarthritis of the hip. $\mathrm{Br} J$ Rheumatol 1997, 36:16-19.

26. Mansell JP, Bailey AJ: Abnormal cancellous bone collagen metabolism in osteoarthritis. J Clin Invest 1998, 101:1596-1603.

27. Brandt KD: Animal models of osteoarthritis. Biorheology 2002, 39:221-235.

28. Hashimoto S, Creighton-Achermann L, Takahashi K, Amiel D, Coutts RD, Lotz M: Development and regulation of osteophyte formation during experimental osteoarthritis. Osteoarthritis Cartilage 2002, 10:180-187.

29. Janusz MJ, Bendele AM, Brown KK, Taiwo YO, Hsieh L, Heitmeyer SA: Induction of osteoarthritis in the rat by surgical tear of the meniscus: Inhibition of joint damage by a matrix metalloproteinase inhibitor. Osteoarthritis Cartilage 2002, 10:785-791.

30. Aigner T, Zien A, Gehrsitz A, Gebhard PM, McKenna L: Anabolic and catabolic gene expression pattern analysis in normal versus osteoarthritic cartilage using complementary DNA-array technology. Arthritis Rheum 2001, 44:2777-2789.

31. Appleton CT, McErlain DD, Henry JL, Holdsworth DW, Beier F: Molecular and histological analysis of a new rat model of experimental knee osteoarthritis. Ann N Y Acad Sci 2007, 1117:165-174.

32. Bau B, Gebhard PM, Haag J, Knorr T, Bartnik E, Aigner T: Relative messenger RNA expression profiling of collagenases and aggrecanases in human articular chondrocytes in vivo and in vitro. Arthritis Rheum 2002, 46:2648-2657.

33. Daouti S, Latario B, Nagulapalli S, Buxton F, Uziel-Fusi S, Chirn GW, Bodian D, Song C, Labow M, Lotz M, Quintavalla J, Kumar C: Development of comprehensive functional genomic screens to identify novel mediators of osteoarthritis. Osteoarthritis Cartilage 2005, 13:508-518.

34. Hellio Le Graverand MP, Reno C, Hart DA: Heterogenous response of knee cartilage to pregnancy in the rabbit: assessment of specific mRNA levels. Osteoarthritis Cartilage 2000, 8:53-62

35. Salminen H, Perala M, Lorenzo P, Saxne T, Heinegard D, Saamanen AM, Vuorio E: Up-regulation of cartilage oligomeric matrix protein at the onset of articular cartilage degeneration in a transgenic mouse model of osteoarthritis. Arthritis Rheum 2000, 43:1742-1748.

36. Watters JW, Cheng C, Pickarski M, Wesolowski GA, Zhuo Y, Hayami T, Wang W, Szumiloski J, Phillips RL, Duong IT: Inverse relationship between matrix remodeling and lipid metabolism during osteoarthritis progression in the STR/Ort mouse. Arthritis Rheum 2007, 56:2999-3009.

37. Kamekura S, Hoshi K, Shimoaka T, Chung U, Chikuda H, Yamada T, Uchida M, Ogata N, Seichi A, Nakamura K, Kawaguchi H: Osteoarthritis development in novel experimental mouse models induced by knee joint instability. Osteoarthritis Cartilage 2005, 13:632-641.

38. Yoshioka M, Coutts RD, Amiel D, Hacker SA: Characterization of a model of osteoarthritis in the rabbit knee. Osteoarthritis Cartilage 1996, 4:87-98.
39. Billinghurst $R C$, Dahlberg L, lonescu $M$, Reiner $A$, Bourne $R$, Rorabeck $C$, Mitchell P, Hambor J, Diekmann O, Tschesche H, Chen J, Van Wart H, Poole AR: Enhanced cleavage of type II collagen by collagenases in osteoarthritic articular cartilage. J Clin Invest 1997, 99:1534-1545.

40. Caterson B, Flannery CR, Hughes CE, Little CB: Mechanisms involved in cartilage proteoglycan catabolism. Matrix Biol 2000, 19:333-344.

41. Neuhold LA, Killar L, Zhao W, Sung ML, Warner L, Kulik J, Turner J, Wu W, Billinghurst C, Meijers T, Poole AR, Babij P, DeGennaro L: Postnatal expression in hyaline cartilage of constitutively active human collagenase-3 (MMP-13) induces osteoarthritis in mice. J Clin Invest 2001, 107:35-44.

42. Lorenz H, Wenz W, Ivancic M, Steck E, Richter W: Early and stable upregulation of collagen type II, collagen type I and YKL40 expression levels in cartilage during early experimental osteoarthritis occurs independent of joint location and histological grading. Arthritis Res Ther 2005, 7:R156-R165.

43. de Crombrugghe B, Lefebvre V, Behringer RR, Bi W, Murakami S, Huang W: Transcriptional mechanisms of chondrocyte differentiation. Matrix Biol 2000, 19:389-394.

44. Gelse K, Soder S, Eger W, Diemtar T, Aigner T: Osteophyte developmentmolecular characterization of differentiation stages. Osteoarthritis Cartilage 2003, 11:141-148.

45. Mapp Pl, Avery PS, McWilliams DF, Bowyer J, Day C, Moores S, Webster R, Walsh DA: Angiogenesis in two animal models of osteoarthritis. Osteoarthritis Cartilage 2008, 16:61-69.

46. Hayami T, Pickarski M, Wesolowski GA, McLane J, Bone A, Destefano J, Rodan GA, Duong IT: The role of subchondral bone remodeling in osteoarthritis: reduction of cartilage degeneration and prevention of osteophyte formation by alendronate in the rat anterior cruciate ligament transection model. Arthritis Rheum 2004, 50:1193-1206.

47. Karsenty G: Transcriptional control of skeletogenesis. Annu Rev Genomics Hum Genet 2008, 9:183-196.

48. Bauer DC, Hunter DJ, Abramson SB, Attur M, Corr M, Felson D, Heinegard D, Jordan JM, Kepler TB, Lane NE, Saxne T, Tyree B, Kraus VB: Classification of osteoarthritis biomarkers: a proposed approach. Osteoarthritis Cartilage 2006, 14:723-727.

49. Wei T, Kulkarni NH, Zeng QQ, Helvering LM, Lin X, Lawrence F, Hale L, Chambers MG, Lin C, Harvey A, Ma YL, Cain RL, Oskins J, Carozza MA, Edmondson DD, Hu T, Miles RR, Ryan TP, Onyia JE, Mitchell PG: Analysis of early changes in the articular cartilage transcriptisome in the rat meniscal tear model of osteoarthritis: pathway comparisons with the rat anterior cruciate transection model and with human osteoarthritic cartilage. Osteoarthritis Cartilage 2010, 18:992-1000.

\section{Pre-publication history}

The pre-publication history for this paper can be accessed here: http://www.biomedcentral.com/1471-2474/12/197/prepub

doi:10.1186/1471-2474-12-197

Cite this article as: Pickarski et al:: Molecular changes in articular cartilage and subchondral bone in the rat anterior cruciate ligament transection and meniscectomized models of osteoarthritis. BMC Musculoskeletal Disorders 2011 12:197.

\section{Submit your next manuscript to BioMed Central and take full advantage of:}

- Convenient online submission

- Thorough peer review

- No space constraints or color figure charges

- Immediate publication on acceptance

- Inclusion in PubMed, CAS, Scopus and Google Scholar

- Research which is freely available for redistribution 